Capel, S., Zwozdiak-Myers, P. and Lawrence, J. (2004) Exchange of information about physical education to support the transition of pupils from primary and secondary school.

Educational Research, 46 (3), 283-300

\title{
Exchange of information about physical education to support the transition of pupils from primary and secondary school
}

\section{Susan Capel, Paula Zwozdiak-Myers and Julia Lawrence Brunel University}

Key words: continuity; liaison activities; progression; transfer from primary to secondary school

\begin{abstract}
The purpose of this study was to identify how information about physical education is exchanged between secondary schools and their respective feeder primary schools, what information is exchanged and how this information is used. A secondary purpose was to look at whether there is any relationship between schools engaging in liaison activities and exchanging information about physical education and between exchanging information and the number of associated secondary schools to which pupils are sent or feeder primary schools from which pupils are received. Questionnaires were sent to 177 secondary and 538 feeder primary schools. Responses from 80 secondary schools and 299 primary schools showed that the highest percentage of teachers exchanged information through written documentation, followed by discussion at cross phase liaison meetings. The type of information exchanged by the highest percentage of teachers was identified as generic information about Key Stage 2 and 3 of the National Curriculum for Physical Education (NCPE) areas of activity and schemes of work, rather than information about the specific physical education content covered or information about individual pupils, such as levels of attainment or ability. Further, results suggest that information may be used for pastoral purposes and that only a small percentage of teachers used the information exchanged to plan for continuity and progression in the physical education curriculum. There was a significant positive relationship between engagement in liaison activities and information received about the physical education curriculum followed by pupils, but a significant negative relationship for primary teachers between the number of different secondary schools to which pupils’ progress and knowledge about the Key Stage 3 schemes of work that Year 6 pupils will follow in their associated secondary schools. These results are discussed in relation to continuity and progression in physical education in the transfer of pupils from primary to secondary schools.
\end{abstract}




\section{INTRODUCTION}

The introduction by the government in England of initiatives such as league tables has created a wealth of information available to schools and to parents. One purpose of this information is for interested parties to be able to judge the success of schools in terms of pupils' attainment. The information available is based largely on that which schools are required statutorily to report, including the results of Statutory Assessment Tests, taken by pupils at the end of Key Stages 1, 2 and $3^{1}$ (ages 7, 11 and 14) in the core subjects of English, mathematics and science ${ }^{2}$. This has resulted in the curriculum focus in primary schools and information available at the time of pupil transfer from primary to secondary school, being largely in relation to these three core subjects. This is supported by results of research (e.g., Featonby, 1998) which has suggested that most liaison activities during the transfer of pupils from primary to secondary school occur in relation to the core subjects. This focus on core subjects may be detrimental to subjects such as physical education.

Continuity and progression are regarded as essential components of education if pupils are to develop to their maximum potential (Birmingham Education Development Centre, 1975). Thus, in order to raise standards of attainment, pupils need to follow a curriculum that is progressive and has continuity. However, the Office for Standards in Education (OFSTED), reporting on the effectiveness of transfer arrangements between schools, concluded that 'Continuity in the curriculum and progression in learning as pupils move from primary to secondary schools are longstanding weaknesses of the educational system' (OFSTED, 2002, p.2). Despite the fact that 'the National Curriculum framework and its associated assessment arrangements are designed to promote continuity in the curriculum and in pupils' progress within and between each key stage in all subjects' (School Curriculum and Assessment Authority (SCAA, 1996, p.4), evidence (e.g. Howarth and Head, 1988; Capel et al, 2003) has suggested that continuity and progression in physical education may not always occur between Key Stages 2 and 3. This suggests that priority given to continuity and progression in the foundation subjects is low when compared to the focus on continuity and

\footnotetext{
${ }^{1}$ The majority of schools in England are organised as primary (ages 5-11 years); and secondary (ages 11-16 or 11-18 years). In relation to the Key Stages of the National Curriculum, primary aligns with Key Stage 1 (5-7 years) and Key Stage 2 (7-11 years) and secondary with Key Stage 3 (11-14 years) and Key Stage 4 (14-16 years, i.e. the end of compulsory schooling).

${ }^{2}$ The National Curriculum in England consists of three core subjects - English, mathematics and science and eight foundation subjects - art, design technology, geography, history, information and communications technology, modern foreign languages, music, physical education. Citizenship became statutory at Key Stage 3 in September 2002.
} 
progression in the core subjects as well as in comparison to initiatives such as the National Strategies for numeracy and literacy.

Jones and Jones (1993) identified the need to promote continuity and progression in order that pupils avoid following a circular curriculum whereby they repeat tasks previously covered, to the detriment of the spiral curriculum provided by the national curriculum. They identified a dip in levels of attainment and motivation as consequences of a lack of consistency between primary and secondary schools, a view supported by Simpson and Goulder (1998). Ellis (1999), looking at the transition from Key Stages 2 to 3, also identified a reduction in pupils' levels of attainment during this period, identifying a possible cause as a reluctance by secondary school staff to take into account the work previously covered within the primary school. Gorwood (1991), looking at the impact of the introduction of the National Curriculum, identified advantages of good liaison as increased understanding between primary and secondary colleagues, changes to teaching styles and increased motivation of pupils.

Information exchanged in the transfer from primary to secondary schools can be in relation to curriculum coverage - either generic information about the Key Stage 2 and 3 curriculum or specific information about the curriculum followed by pupils in a school - or information about individual pupils attainment or progress. The National Foundation for Educational Research (NFER, 1995) identified the key requirements for the transfer of information as information relevant to the curriculum taught and information regarding pupils levels of attainment. Further, information can be used for a number of purposes, including curriculum planning, providing a progressive curriculum for individual pupils and to support the pastoral transition of pupils from primary to secondary school. These different foci require the exchange of different information.

McCallum (1996) identified the need for primary schools to pass information to the secondary school about the core subjects of English, mathematics and science. Regular meetings and visits to both primary and secondary schools were identified as the main ways in which information was transferred between primary and secondary schools. The use of transfer sheets provided standardisation in the information transferred, although such sheets focused more on pastoral information than curriculum content. The study concluded that the use of the information transferred was limited, with a tendency by secondary staff to mistrust the information they had been given.

Jarman (1990), looking at primary-secondary continuity in science, highlighted the type of information transferred between schools as one of the constraints to the progression of pupils' 
knowledge resulting in unnecessary duplication. One reason advanced by Lance (1994) may be that information exchanged is not perceived as relevant. Lance also suggested that 'Teachers do not automatically refer to their pupil's case records when teaching them for the first time in the same way that doctor's are trained to do. Teachers suspect their colleagues' judgements and prefer to rely on their own diagnosis' (p.47). If information is not used to inform planning, it may be, as Gorwood (1991) suggested in relation to mathematics, that secondary school teachers start pupils on work that is below the standard they have achieved in primary school. He suggested that this might be due to an inability or lack of willingness by staff in secondary schools to adjust their teaching styles and approaches.

OFSTED (2002), in their evaluation report focussing on the transfer arrangements in operation between primary and secondary schools, identified a decline in progress on transfer. This was partly due to a lack of collaboration between primary and secondary schools, with a tendency by secondary schools whose intake came from a large number of primary schools to work more closely with their main feeder primary schools. Whilst the need to promote curriculum continuity was evident, there was a tendency to focus on the promotion of pastoral rather than academic progress.

There has, however, been little research specifically in relation to physical education in the transfer of pupils from primary to secondary school. It is important to undertake this research, particularly as it might not be relevant to compare studies on progression and continuity in other subjects, including science and mathematics, with physical education, due to differences in the format of the physical education curriculum as compared to other subjects. In physical education, the same areas of activity, activities and therefore the same skills are covered at Key Stage 2 and Key Stage 3. This requires children to practice and repeat basic skills to enable them to build on and develop their skills in these areas. Although this is true to some extent in science and mathematics, there is a greater emphasis on gaining new knowledge in a range of topics.

If the physical education curriculum is to be progressive from primary to secondary school, then teachers should familiarise themselves with the curriculum that pupils have followed prior to transfer. They also need to be familiar with the progress of individual pupils if their learning is to be continuous and standards are to be raised. However, Talbot (1996) suggested that physical education teachers may not receive the right information, nor have the necessary background to enable them effectively to develop a progressive curriculum from primary to secondary school. She stated that 'teachers of physical education need to know and understand a great deal more about the principles of progression, and about the previous experiences and achievements of the children they teach. In order 
for children to progress, their previous achievements must be recognised, valued and built upon: it is all too common for children on entry to secondary schools to have to repeat work which they have covered in primary schools, because some of their peers may not have covered the same work' (p.6).

The purpose of the present study was to identify how information about physical education is exchanged between secondary schools and their respective feeder primary schools, what information is exchanged and how this information is used - particularly whether it is taken into account in planning for continuity and progression. A secondary purpose was to look at whether there is any relationship between schools engaging in liaison activities and exchanging information about the physical education curriculum of feeder primary schools or associated secondary schools and also exchanging information and the number of schools to which pupils are sent or from which pupils are received.

\section{METHODOLOGY}

\section{Subjects}

Schools in five Local Education Authorities (LEAs) in England, representing four county authorities and one London Borough, were included in this research. All state secondary schools that had an intake of pupils from primary schools at the beginning of Year 7 (the start of Key Stage 3) were included ( $n=177$ ), along with feeder primary schools of those secondary schools that responded to the questionnaire ( $\mathrm{n}=538$ ). Responses were received from 80 (45\%) secondary heads of physical education departments (77 teaching in mixed gender schools, 1 in a girls' school and 2 in boys' schools) and from 299 (56\%) primary headteachers or physical education co-ordinators. The size of secondary schools ranged from 300 to 1850 pupils and the size of primary schools ranged from 22 to 810 pupils. The number of primary schools from which secondary teachers identified that they received pupils ranged from 3 to 60 schools. The number of secondary schools to which primary teachers identified that they sent pupils ranged from 1 to 16 schools. Further detail about the size of schools and number of schools pupils were received from or sent to is given in Table 1.

Table 1: School roll and number and percentage of schools pupils were received from or sent to

\begin{tabular}{|l|l|l|l|}
\hline \multicolumn{2}{|c|}{ Secondary schools } & \multicolumn{2}{c|}{ Primary schools } \\
\hline $\begin{array}{l}\text { Number of pupils on } \\
\text { roll }\end{array}$ & $\begin{array}{l}\text { Number (and } \\
\text { percent) of schools }\end{array}$ & $\begin{array}{l}\text { Number of pupils on } \\
\text { roll }\end{array}$ & $\begin{array}{l}\text { Number (and } \\
\text { percent) of schools }\end{array}$ \\
\hline $300-699$ pupils & $14(17.5 \%)$ & 22 to 99 pupils & $68(22.7 \%)$ \\
\hline $700-1099$ pupils & $35(43.75 \%)$ & 100 to 199 pupils & $74(24.7 \%)$ \\
\hline
\end{tabular}




\begin{tabular}{|l|l|l|l|}
\hline $1100-1499$ pupils & $19(23.75 \%)$ & 200 to 299 pupils & $72(24.1 \%)$ \\
\hline $1500-1850$ pupils & $11(13.75 \%)$ & 300 to 399 pupils & $49(16.4 \%)$ \\
\hline unknown & $1(1.25 \%)$ & 400 to 499 pupils & $23(7.7 \%)$ \\
\hline & & $500-810$ pupils & $11(3.7 \%)$ \\
\hline TOTAL & $80(100 \%)$ & unknown & $2(0.7 \%)$ \\
\hline & & TOTAL & $299(100 \%)$ \\
\hline $\begin{array}{l}\text { Number of primary } \\
\text { feeder schools pupils } \\
\text { received from }\end{array}$ & $\begin{array}{l}\text { Number (and } \\
\text { percent) of schools }\end{array}$ & $\begin{array}{l}\text { Number of } \\
\text { secondary schools } \\
\text { pupils sent to }\end{array}$ & $\begin{array}{l}\text { Number (and } \\
\text { percent) of schools }\end{array}$ \\
\hline 3-5 schools & $21(26.1 \%)$ & 1 school & $68(22.7 \%)$ \\
\hline 6-10 schools & $41(51.1 \%)$ & 2 schools & $55(18.4 \%)$ \\
\hline $11-15$ schools & $6(7.6 \%)$ & 3 schools & $52(17.4 \%)$ \\
\hline 16-30 schools & $6(7.6 \%)$ & 4 schools & $39(13.1 \%)$ \\
\hline & $6(7.6 \%)$ & 5 schools & $27(9.0 \%)$ \\
\hline & & 6 schools & $33(11.1 \%)$ \\
\hline & & 7 to 10 schools & $15(5.0 \%)$ \\
\hline & & 11 to 16 schools & $3(1.0 \%)$ \\
\hline TOTAL & $80(100 \%)$ & TOTAL & $7(2.3 \%)$ \\
\hline
\end{tabular}

\section{Instruments and procedures}

\section{Questionnaires}

The questionnaires sent to secondary and primary schools contained a number of open and closed questions asking how information about physical education is exchanged between secondary schools and their feeder primary schools, what information is exchanged and how this information is used particularly whether it is taken into account in planning for continuity and progression.

Prior to undertaking the main study, the questionnaires were piloted with a sample of 12 secondary and 12 primary teachers. As well as completing the questionnaire, teachers were asked to comment on the clarity and appropriateness of the questions, instructions and accompanying letter. As a result, some modifications were made to the wording of some questions, the accompanying letter and instructions for completing the questionnaire, as well as some changes to the format and layout of the questionnaire.

Questionnaires were sent to the head of the physical education department in secondary schools in March 2001. After three weeks a reminder letter was sent, followed by a second reminder and second questionnaire after a further four weeks. After a questionnaire was returned by a secondary school, a questionnaire was sent to the headteacher of all its' feeder primary schools, followed by a reminder 
letter and second questionnaire after two weeks. Primary school questionnaires were sent out over a six week period between May and July 2001. The number of questionnaires sent to primary schools following receipt of each questionnaire completed by a secondary school varied according to the number of feeder primary schools feeding into each secondary school. Primary schools were sent one questionnaire only, irrespective of the number of secondary schools to which they sent pupils. They were not asked to respond in relation to one secondary school, rather they responded in regard to all secondary schools to which they send pupils

\section{Data analysis}

Analysis of the quantitative data generated by the questionnaires was undertaken using the Statistical Package for the Social Sciences (SPSS). Numbers and percentages were calculated for most responses. Pearson Product Moment Correlation analysis was used to identify any relationship between schools engaging in liaison activities and exchanging information about the physical education curriculum and exchanging information and the number of schools to which pupils are sent or from which pupils are received.

Note that in the results not all numbers add up to 80 (secondary) or 299 (primary) as some teachers did not answer every question or provided more than one answer to a given question.

\section{RESULTS}

\section{How information about physical education is exchanged}

A total of 42 responses to this question were received from secondary teachers. The highest percentage of these 42 secondary teachers identified that information is exchanged through written documentation, then formalised discussion during cross phase liaison meetings, followed by information being exchanged on a casual, informal basis, either during school visits or by word of mouth from ex-pupils. A total of 232 responses to this question were received from primary teachers in relation to how information about the physical education curriculum was exchanged during the transfer process. The highest percentage of these 232 primary teachers identified that information is exchanged through written documentation (which includes specific transfer document forms or discs, school reports and End of Key Stage levels), followed by formalised discussion during cross phase liaison meetings, then information exchanged through school reports; visits to the primary school by secondary subject specialists; using assessment sheets which reflect End of Key Stage levels; and 
visits by primary pupils to associated secondary schools. These results are shown in Tables 2 (secondary) and 3 (primary).

Table 2: How secondary teachers identified information about physical education was exchanged with feeder primary schools (in rank order)

\begin{tabular}{|l|l|}
\hline How information is exchanged with primary feeder schools & $\begin{array}{l}\text { Number (\%) schools } \\
\text { responding to the } \\
\text { question }\end{array}$ \\
\hline $\begin{array}{l}\text { written documentation, such as pupils school reports, records of achievement } \\
\text { and/or transfer documents, key stage 2 schemes of work and lists of activities } \\
\text { taught }\end{array}$ & $19(45.3 \%)$ \\
\hline formalised discussion during Year 6/Year 7 cross phase liaison meetings & $9(21.4 \%)$ \\
\hline Discussion on a casual, informal basis & $7(16.7 \%)$ \\
\hline Discussion during schools visits & $3(7.1 \%)$ \\
\hline through 'word of mouth' from ex-pupils & $3(7.1 \%)$ \\
\hline through the induction process & $1(2.4 \%)$ \\
\hline
\end{tabular}

No response was received from 38 teachers, i.e. $47.5 \%$ of the sample

Table 3: How primary teachers identified information about physical education was exchanged with associated secondary schools (in rank order)

\begin{tabular}{|l|l|}
\hline How information is exchanged with secondary schools & $\begin{array}{l}\text { Number (\%) schools } \\
\text { responding to the } \\
\text { question }\end{array}$ \\
\hline $\begin{array}{l}\text { specific transfer document forms or discs, generated by the DfES, LEA or } \\
\text { associated secondary schools; also, curriculum information in the form of a } \\
\text { summary sheet }\end{array}$ & $57(24.6 \%)$ \\
\hline formalised discussion during Year 6/Year 7 cross phase liaison meetings & $48(20.7 \%)$ \\
\hline $\begin{array}{l}\text { school reports that include pupils' Record of Achievement, profile, National } \\
\text { Curriculum records and End of Key Stage Descriptions }\end{array}$ & $46(19.8 \%)$ \\
\hline $\begin{array}{l}\text { visits made to primary school by physical education subject specialists either to } \\
\text { introduce Year 7 physical education, observe Key Stage 2 lessons, provide } \\
\text { support to primary teachers, or to lead Key Stage 2 classes }\end{array}$ & $26(11.2 \%)$ \\
\hline using assessment sheets which reflect End of Key Stage levels & $20(8.6 \%)$ \\
\hline Discussion during visits of primary pupils to associated secondary schools & $18(7.8 \%)$ \\
\hline informally through discussions & $14(6.0 \%)$ \\
\hline Joint team teaching activities & $2(0.9 \%)$ \\
\hline via newsletters & $1(0.4 \%)$ \\
\hline
\end{tabular}

No response was received from 67 schools, i.e. $22 \%$ of the sample

\section{What information about physical education is exchanged}

\section{Information secondary teachers identified receiving from primary schools}

Of a total of 77 responses to this question, 24 secondary teachers indicated that some information is received from all or some feeder primary schools about Key Stage 2 physical education content, whilst 53 secondary teachers indicated that no information is received. Table 4 shows that the highest percentage of these 24 secondary teachers identified that the information received from feeder 
primary schools is related to Key Stage 2 National Curriculum for Physical Education (NCPE) areas of activity and schemes of work covered. A lower percentage of teachers identified information received about individual pupils, including a general statement about pupils' aptitude, sporting interest and ability or details either of pupils' swimming ability, and/or information about National Curriculum levels achieved.

Table 4: What information secondary teachers identified receiving from feeder primary schools

\begin{tabular}{|l|l|}
\hline $\begin{array}{l}\text { Number (\%) } \\
\text { schools } \\
\text { responding to } \\
\text { the question }\end{array}$ & What information is received from feeder primary schools \\
\hline $53(69 \%)$ & No information received from feeder primary schools \\
\hline $24(31 \%)$ & Some information received from feeder primary schools, as below \\
\hline Information about the curriculum \\
\hline $17(70.8 \%)$ & information about Key Stage 2 NCPE areas of activity and schemes of work covered \\
\hline Information about individual pupils \\
\hline $5(20.8 \%)$ & $\begin{array}{l}\text { a general statement about pupils' aptitude, sporting interest and ability or details of } \\
\text { pupils' swimming ability }\end{array}$ \\
\hline $2(8.4 \%)$ & information about National Curriculum levels achieved \\
\hline Total & \\
\hline $24(100 \%)$ & Total \\
\hline
\end{tabular}

\section{Information primary teachers identified giving to secondary schools}

Of a total of 261 responses to this question, 143 primary teachers indicated that they give information to all or some of their associated secondary schools about Key Stage 2 physical education, whilst 118 reported that they do not give any information to any of their associated secondary schools. Of the 143 primary schools indicating that they give information to all or some associated secondary schools, 383 responses in relation to what information is given to secondary schools were identified. Table 5 shows that the highest percentage of the 143 primary teachers who gave information to all/some of their associated secondary schools identified that information about individual pupils is given to secondary schools - including information about pupils’ progress, ability, achievement and attitude in a generic section of the school report; End of Key Stage levels of attainment achieved by pupils in physical education; information about individual pupils' strengths, outstanding skills and successes; teams represented and extra curricular activities pursued; special educational needs; and suggested targets for pupils' to address to further personal improvement. Some teachers indicated that they make an informal comment or statement. A lower percentage of teachers indicated that information is included about the Key Stage 2 areas of activity and schemes of work and QCA link units pupils have covered.

Table 5: What information primary teachers identified giving to associated secondary schools 


\begin{tabular}{|l|l|}
\hline $\begin{array}{l}\text { Number (\%) } \\
\text { schools } \\
\text { responding to } \\
\text { the question }\end{array}$ & What information is given to associated secondary schools \\
\hline $118(45 \%)$ & No information given to associated secondary schools \\
\hline $143(55 \%)$ & Some information given to associated secondary schools, with 383 responses, as below \\
\hline Information about individual pupils \\
\hline $185(48.3 \%)$ & $\begin{array}{l}\text { a generic section of the school report which includes information about pupils' } \\
\text { progress, ability, achievement and attitude }\end{array}$ \\
\hline $52(13.6 \%)$ & the End of Key Stage levels of attainment in physical education \\
\hline $37(9.6 \%)$ & pupils' strengths, outstanding skills and successes \\
\hline $26(6.8 \%)$ & an informal comment or statement \\
\hline $24(6.3 \%)$ & teams represented and extra curricular activities pursued \\
\hline $8(2.1 \%)$ & pupils' with special educational needs \\
\hline $2(0.5 \%)$ & Suggested targets for pupils' to address to further personal improvement \\
\hline Information about the curriculum \\
\hline $49(12.8 \%)$ & $\begin{array}{l}\text { the Key Stage } 2 \text { areas of activity, schemes of work and QCA link units pupils have } \\
\text { covered }\end{array}$ \\
\hline
\end{tabular}

Knowing how and what information is exchanged between secondary and primary teachers has limited value unless that information is actively taken into account and considered to be of relevance by teachers when planning for continuity and progression between Key Stages 2 and 3. The next section of the paper looks at how information exchanged is used - particularly whether it is taken into account when planning for continuity and progression in physical education from Key Stage 2 to 3.

\section{How information is used}

\section{Information used about individual pupils}

Of a total of 75 responses to this question, 40 secondary teachers indicated that the Key Stage 2 records of incoming Year 7 pupils had been read (18 had read the records of all incoming pupils, whilst 22 had read some) and 35 indicated that they had not read any of the Key Stage 2 records of incoming year 7 pupils. Of the 40 secondary teachers who indicated that they had read the Key Stage 2 records of incoming Year 7 pupils, 28 indicated reasons for reading these as follows: 10 reported reading records in a pastoral context (academic and medical); 8 in the context of physical education; and a further 10 in a combination of both contexts. However, of a total of 52 responses, only 6 secondary teachers indicated that the Key Stage 2 records of incoming pupils influenced, fully or partially, planning of the Year 7 physical education curriculum, whereas 46 indicated that these records did not influence planning of the Year 7 curriculum. 
Of a total of 78 responses to this question, 16 primary teachers reported that secondary physical education teachers use pupils' Year 6 records when planning the Year 7 physical education curriculum. Of these 4 were used by all associated secondary schools and 12 by some of them. Sixtytwo primary teachers indicated that secondary physical education teachers do not use pupils' Year 6 records when planning the Year 7 physical education curriculum.

\section{Information used in planning physical education schemes of work}

Of a total of 77 responses to this question, 36 secondary teachers indicated that Key Stage 2 physical education schemes of work are taken into account when planning Year 7 schemes of work. Of these, 32 indicated that Key Stage 2 schemes of work are fully taken into account and four indicated that these are partially taken into account. Forty-one secondary teachers reported that they do not take Key Stage 2 physical education schemes of work into account when planning Year 7 schemes of work.

Of a total of 290 responses to this question, 28 primary teachers indicated that the Year 7 physical education curriculum pupils will be taught in their secondary schools are taken into account when planning Year 6 schemes of work. Of these, 12 indicated that the Year 7 physical education curriculum is fully taken into account and 16 indicated that these are partially taken into account. Two hundred and sixty two reported that they do not take the Year 7 physical education curriculum into account at all when planning Year 6 schemes of work.

Of the 36 secondary teachers who indicated that they take account of pupils' Key Stage 2 physical education curriculum when planning Year 7 schemes of work, 65 responses were received concerning how the physical education curriculum has been taken into account. Of the 28 primary teachers who indicated that the Year 7 physical education curriculum pupils will progress to is taken into account when planning Year 6 schemes of work, 61 responses were received concerning how the physical education curriculum has been taken into account. Responses are shown in Table 6.

Table 6 shows that when planning year 7 schemes of work secondary teachers take into account generic information about the Key Stage 2 curriculum, with some account taken of the specific Key Stage 2 physical education curriculum followed by schools from which pupils are received and, to a lesser extent, information about individual pupils. The highest percentage of secondary teachers who responded reported that an awareness of the Key Stage 2 National Curriculum requirements for physical education, including QCA link units, is used in developing the Key Stage 3 schemes of 
work. A lower percentage of teachers reported that they build Key Stage 3 schemes of work on specific Key Stage 2 physical education curriculum followed by pupils, and use information gained about feeder primary schools’ physical education provision through personal experience. Other teachers indicated they used information about pupils' standards, achievements and abilities from documentation or personal experience to differentiate pupils into ability groupings. Some responses indicated that the information is not used to inform continuity and progression - since teachers' use internally designed bridging units or foundation courses, begin at a basic level or administer assessments to gauge levels of knowledge and skill, i.e. they make their own judgement of pupils' attainment.

The number of primary teachers who took account of the Key Stage 3 physical education curriculum in planning was low. However, of this number, results show that the highest percentage of primary teachers who responded indicated that Key Stage 2 schemes of work are designed based on specific information about the physical education curriculum followed by schools to which pupils transfer, for example, knowledge of Key Stage 3 schemes of work and the use of a physical education curriculum map during planning; and, sharing physical education curriculum planning and mapping directly with the secondary schools to which primary pupils progress. However, the use of generic information was also reported, for example, following the Key Stage 2 NCPE and relating this to Key Stage 3 NCPE; using QCA link units.

These results suggest that teachers use both their general knowledge of Key Stage 2 or Key Stage 3 requirements and specific knowledge about the Key Stage 2 or Key Stage 3 physical education curriculum followed by pupils. Secondary teachers also used information about individual pupils to inform progression. However, some teachers start from scratch with foundation courses and/or initial assessment of pupils.

Table 6: How pupils' year 6 or year 7 physical education experiences are taken into account when planning schemes of work

\begin{tabular}{|c|c|c|}
\hline $\begin{array}{l}\text { No. }(\%) \\
\text { secondary } \\
\text { schools } \\
\text { responding to } \\
\text { the question }\end{array}$ & $\begin{array}{l}\text { Year } 6 \text { or } 7 \text { physical education experiences that inform planning } \\
\text { for Year } 7 \text { physical education schemes of work }\end{array}$ & $\begin{array}{l}\text { No. }(\%) \\
\text { primary } \\
\text { schools } \\
\text { responding to } \\
\text { the question }\end{array}$ \\
\hline $41(53 \%)$ & Experiences not taken into account & $262(90 \%)$ \\
\hline $36(47 \%)$ & $\begin{array}{l}\text { Experiences taken into account, as below (number and type of } \\
\text { response) }\end{array}$ & $28(10 \%)$ \\
\hline \multicolumn{3}{|c|}{ Generic information about the physical education curriculum } \\
\hline $18(27.8 \%)$ & $\begin{array}{l}\text { Following, or from an awareness of, the requirements of Key Stage } 2 \\
\text { NCPE and relating this to Key Stage } 3 \text { NCPE }\end{array}$ & $21(34.4 \%)$ \\
\hline
\end{tabular}




\begin{tabular}{|c|c|c|}
\hline $6(9.2 \%)$ & use of QCA link units or internally designed bridging units & $12(19.7 \%)$ \\
\hline \multicolumn{3}{|c|}{ Specific information about the physical education curriculum } \\
\hline $13(20 \%)$ & $\begin{array}{l}\text { Key Stage } 3 \text { schemes of work built on Key Stage } 2 \text { or Key Stage } 3 \\
\text { experiences }\end{array}$ & $23(37.7 \%)$ \\
\hline \multirow[t]{2}{*}{$4(6.1 \%)$} & $\begin{array}{l}\text { from personal knowledge and experience gained about feeder primary } \\
\text { schools' physical education provision and standards }\end{array}$ & \\
\hline & $\begin{array}{l}\text { exchange curriculum planning and mapping with associated secondary } \\
\text { schools }\end{array}$ & $5(8.2 \%)$ \\
\hline \multicolumn{3}{|c|}{ Information about individual pupils } \\
\hline $8(12.3 \%)$ & $\begin{array}{l}\text { use information received about pupils' achievements and experience } \\
\text { from the school, parents, pupils themselves, clubs or community links }\end{array}$ & \\
\hline $5(7.7 \%)$ & use a differentiated approach with ability groupings & \\
\hline \multicolumn{3}{|c|}{ Information not used } \\
\hline $6(9.2 \%)$ & use foundation courses and begin at a basic level & \\
\hline $5(7.7 \%)$ & administer assessments to gauge levels of knowledge and skill & \\
\hline \multicolumn{3}{|l|}{ Total } \\
\hline $65(100 \%)$ & Total & $61(100 \%)$ \\
\hline
\end{tabular}

\section{Correlation analysis}

There was a significant positive relationship ( $\mathrm{p}=0.002$ ) between secondary teachers being engaged in liaison activities with feeder primary schools and information received about physical education in which pupils have been engaged in primary schools. There was also a significant positive relationship ( $\mathrm{p}=0.018$ ) between primary teachers being engaged in liaison activities with associated secondary schools and these secondary schools knowing what pupils' have covered in physical education at Key Stage 2. There was a significant negative relationship $(p=-0.004)$ for primary teachers between the number of different secondary schools to which pupils' progress after Year 6 and knowledge about the Key Stage 3 schemes of work that Year 6 pupils will follow in their associated secondary schools. There was no significant relationship for secondary teachers between the number of different primary schools from which pupils are received and knowledge about the Key Stage 2 schemes of work that Year 6 pupils have followed.

\section{DISCUSSION}

Results from this study must be treated with caution due to certain limitations of the study and of the questionnaire. The size of sample was relatively small, which makes it difficult to generalise to other schools. Further, there was a low response to some questions (e.g. $48 \%$ of secondary teachers and $22 \%$ of primary teachers did not indicate how information about physical education is exchanged (Tables 2 and 3)). In addition, although the content of the questionnaire provided much relevant information, its scope was limited. It did not probe some questions in depth. Thus, a follow up study 
is needed to investigate some of the questions further. Interviews would be an appropriate method of data collection to probe the answers from this study more fully. Nevertheless, in light of the dearth of empirical research about information exchanged about physical education in the transition from primary to secondary school, the results of this study should provide base-line data for future studies. Further, results suggest some interesting findings in relation to information exchanged between secondary and primary schools to promote continuity and progression in physical education.

\section{How information is exchanged}

Results showed that $52.5 \%$ of secondary teachers and $77.6 \%$ of primary teachers identified that they exchanged information with their feeder primary schools or associated secondary schools, respectively about physical education in the transition from primary to secondary school (from Key Stage 2 to Key Stage 3). This percentage is encouraging in the light of results of previous research (e.g., Featonby, 1998) which has suggested that most liaison activities during the transfer of pupils from primary to secondary school occur in relation to the core subjects. How this information is exchanged during the transfer from primary to secondary school is interesting. The highest percentage of both secondary and primary teachers identified that information is exchanged through written documentation, followed by formalised discussion during cross phase liaison meetings. This suggests that many schools are formally structuring the exchange of information. These results are encouraging as they suggest that the exchange of information is taken seriously, and because documentation (including notes of meetings) can be referred to as and when appropriate. However, the information included in any documentation must be relevant.

\section{What information is exchanged}

Results from secondary and primary teachers in relation to what information is exchanged are interesting. A lower percentage of both secondary and primary teachers identified what information is exchanged between schools than identified how information is exchanged. The reason for this is not clear, but one possible reason might be that some teachers found it difficult to categorise what information is exchanged.

Of those that did identify information exchanged, the highest percentage of secondary teachers identified that information being exchanged with feeder primary schools is information about Key Stage 2 areas of activity and schemes of work - mostly related to generic information about the physical education curriculum, although some exchanged information about the specific curriculum 
followed by pupils in the schools from which the pupils are received. A lower percentage identified information exchanged about individual pupils, including details either of pupils' swimming ability or a general statement about pupils' aptitude, sporting interest and ability and information about National Curriculum levels achieved. This finding was contrary to the finding that a large percentage of primary teachers indicated that secondary schools receive information about individual pupils, e.g. pupils' progress, ability, achievement and attitude, End of Key Stage levels of attainment for the 'six areas of activity', pupils' strengths, outstanding skills and successes, teams represented and extra curricular activities pursued, pupils' with special educational needs and suggested targets for pupils' to address to further personal improvement.

A possible reason for the difference in response between primary and secondary schools could be that secondary teachers look more closely at curriculum information than information about individual pupils. This could be for a number of reasons, including information given to secondary schools by primary schools not being in a format easy for secondary teachers to use (for example, it contains inappropriate information, too much information), lack of standardised transfer forms or information is not seen as relevant and therefore is not used. This supports findings by Jarman (1990) and Lance (1994). It may also be due to mistrust between primary and secondary staff regarding the transfer of information, as identified by McCallum (1996). One reason for this may be that secondary teachers may not want to rely on assessments of pupils undertaken by non-specialist primary teachers. Lance (1994) suggested that assessment of pupils by non-specialist primary teachers means that secondary 'Teachers suspect their colleagues' judgements and prefer to rely on their own diagnosis' (p.47). This may result in secondary teachers not relying on information about individual pupils as reported by primary teachers or information about the Key Stage 2 physical education curriculum followed by pupils - preferring to make a 'fresh start' in Year 7. Further, secondary teachers may not take account of information about individual pupils because they do not know enough about the principles of progression, and about the previous achievements and abilities of the children they teach (Talbot, 1996) and therefore do not appreciate the value of the information provided.

These results suggest that overall the majority of secondary teachers may approach physical education curriculum planning only with a generic overview of the Key Stage 2 physical education curriculum followed by their incoming Year 7 pupils. However, they may take into account information from primary schools about Key Stage 2 areas of activity and schemes of work covered, but only a low percentage take into account the relative levels/standards and schemes of work covered by individual pupils entering Year 7. This relates to the findings of OFSTED (2002) who stated that secondary schools 'generally did not know, in sufficient detail, what their new pupils could do, and they had not 
set targets for improving attainment during Year 7' (p.2). By not using information about pupils' specific Key Stage 2 physical education experiences and/or about individual pupils, secondary teachers may start pupils on work which is below that which they have achieved in the primary school (Gorwood, 1991). It is important, therefore, that information provided by primary schools is relevant and of significance to secondary teachers and that it is provided in an easily accessible format. It is also important that secondary teachers have confidence in the information and build an understanding of the physical education curriculum followed by pupils at Key Stage 2 and about the progress of individual pupils. This may require closer liaison between secondary and primary teachers to agree on the information to be exchanged, when and in what format.

\section{How information is used}

Any information exchanged between secondary and primary teachers can only be effective if it is used. Some possible reasons were suggested above for not using information about individual pupils. Results of this study showed mixed responses, with just over $50 \%$ of secondary teachers indicating that they have read the records of incoming Year 7 pupils. Of these, the majority indicated that they have read the records in a pastoral context or a combination of both pastoral and physical education contexts. Forty seven percent of secondary teachers indicated that these records have influenced their planning of the Year 7 physical education curriculum directly, although some of the additional comments suggested an indirect influence on planning, e.g. this ‘may influence differentiation' and 'usually from a negative aspect'. Further comments by secondary teachers, such as 'we assume they have some knowledge of physical education, the first lesson in each unit establishes how much' and 'they have varied experiences' give an insight into the views of some secondary teachers about using information received to inform their physical education curriculum planning. Thus, results suggest that information is not used explicitly to inform planning for continuity and progression from Key Stage 2 to Key Stage 3.

Although nearly 50\% of secondary teachers reported that pupils’ Key Stage 2 physical education schemes of work are taken into account when planning Year 7 schemes of work, only $10 \%$ of primary teachers indicated that the Year 7 physical education schemes of work that Year 6 pupils will progress to are taken into account when planning Year 6 schemes of work. Results also suggested that where teachers use information in planning many may have done so by taking a generic perspective rather than in relation to the specific physical education curriculum content pupils have followed in Year 6 or are going to follow in Year 7. This is likely to be due to many secondary physical education teachers making assumptions about primary physical education based on the fact that in year 6 pupils 
will have followed the Key Stage 2 programme of study in the National Curriculum for Physical Education.

\section{Correlations}

As would be expected, correlations showed that being engaged in liaison activities with feeder primary schools/associated secondary schools, resulted in more information received about the physical education curriculum followed by pupils in primary schools or which pupils are going to follow in secondary schools, respectively. They also showed a negative correlation identified by primary teachers between the number of different secondary schools to which pupils progress after Year 6 and knowledge about the Key Stage 3 schemes of work that Year 6 pupils will follow in associated secondary schools. These results suggest that it is important to engage in liaison activities with feeder primary schools or associated secondary schools, respectively in order to promote continuity and progression in physical education between Key Stages 2 and 3. However, it seems that this is more difficult for primary schools which send pupils to a number of different secondary schools. Although there was no correlation for secondary schools - there might be an impact, as secondary schools are likely to have a larger intake of pupils in Year 7 from different primary schools that have provided diverse physical education experiences for pupils. There is also likely to be a wealth of documentation for secondary teachers to absorb. Further, larger secondary schools may have a Year 7 intake of more than 200 pupils and time restrictions may prevent them from going through the transfer documentation of every pupil in detail. However, further work is needed to follow this up. Thus, teachers in primary schools that send pupils to a large number of associated secondary schools, along with these associated secondary schools, need to identify ways in which they can overcome these issues.

\section{CONCLUSIONS}

This study has provided some insight into how information is exchanged about physical education, what information is exchanged and how information is used - particularly how it informs continuity and progression in physical education. Results are mixed, suggesting that information is not exchanged consistently between all secondary and primary schools and of those that do exchange information, not all use it to inform continuity and progression. In some schools it is used for pastoral purposes. With the range of priorities in which schools need to be engaged, it is important to identify reasons why some schools prioritise and exchange information about physical education in the transition of pupils from primary to secondary schools and use this to inform planning, whilst others do not. Further information is also needed about whether the formal exchange of information is 
supplemented or replaced by informal exchange in some schools. Results also suggest that where information is exchanged it is more often exchanged in written form or through discussion at formal meetings. This is encouraging as written information can be referred to as and when appropriate. However, the information included in any documentation must be relevant. It must also be in a form which is easily accessible to the intended audience. Further, it must also be read and acted upon if it is to inform planning for continuity and progression in physical education. When the documentation is received is also important, along with who at a secondary school receives it. If documentation takes some time to reach physical education staff it might be received too late for it to inform planning. A case might be made for information about physical education to be given directly to secondary physical education staff before pupils have left primary school, which requires liaison between schools. Other results are less encouraging as they suggest that information exchanged may be generic information about the NCPE rather than information about the specific physical education curriculum followed by pupils or about individual pupils, for example an LEA generated form on which primary teachers tick boxes about areas of activity they have taught without any detail. They also suggest that information exchanged may be used more for pastoral purposes than for specific physical education purposes.

The results of this study provide a broad overview of the practice of these secondary and primary schools in relation to how and what information is exchanged and how information is used. In order to get a better understanding about how best continuity and progression in physical education can be promoted it will be important to identify exactly what information secondary school teachers require to promote continuity in a manageable way. Thus, further research in this area could include case studies of schools (including both secondary schools and their feeder primary schools), involving semi-structured interviews with teachers, to find out more detail about how and what information is exchanged, whether this information is discussed and agreed or just passed from one school to another, when information is exchanged and by whom, and the effectiveness of the documentation to inform planning for continuity and progression in physical education from primary to secondary school (from Key Stage 2 to 3). This research should also look at the extent to which the physical education curriculum followed by individual pupils is taken into account compared to generic knowledge about the physical education curriculum at Key Stages 2 and 3 and, further, how much teachers rely on their knowledge of the NCPE for planning purposes. 


\section{REFERENCES}

Birmingham Education Development Centre (1975) Continuity in Education: Junior to Secondary. Final Report. Birmingham, City of Birmingham Education Department.

Capel, S., Zwozdiak-Myers, P. and Lawrence, J. (2003) A study of current practice in liaison between primary and secondary schools in physical education. European Physical Education Review, 9 (2), 115-135.

Ellis, S. (1999) National Curriculum testing across the interface at KS2 / KS3: A view from the bridge. Curriculum, 20 (1), $38-51$.

Featonby, D.R. (1998) A report on curriculum liaison between junior and secondary schools in County Durham (1997). Curriculum, 19 (2), 68-73.

Gorwood, B. (1991) Primary - secondary transfer after the National Curriculum. School Organisation, 11 (3), 283-290.

Howarth, K. and Head, R. (1988) Curriculum continuity in physical education: A small scale study. British Journal of Physical Education, 19 (6) 241-243.

Jarman, R. (1990) Primary-secondary science continuity: A new ERA? School Science Review, 71 (257), 19-29.

Jones, L.P. and Jones, L. (1993) Keeping up the momentum: improving continuity. Education 3 - 13, October $46-50$.

Lance, A. (1994) The case for continuity. Forum, 36 (2), 46-47.

McCallum, B. (1996) The transfer and use of assessment between primary and secondary schools. British Journal of Curriculum and Assessment, 16 (3), 10 - 14.

National Foundation for Educational Research (1995) Continuity and Progression 5 - 16:

Development in Schools. Slough, NFER.

Office for Standards in Education (OFSTED) (2002) Changing Schools; An Evaluation of the Effectiveness of Transfer Arrangements at Age 11. HMI 550. London, HMSO.

School Curriculum Assessment Authority (1996) Promoting Continuity between Key Stage 2 and Key Stage 3. London, SCAA.

Simpson, M. and Goulder, J. (1998) Promoting continuity and progression. Scottish Educational Review, 30 (1) 15 - 28.

Talbot, M. (1996) Gender and National Curriculum Physical Education. British Journal of Physical Education, Spring, 5-7. 